Acta Technologica Agriculturae 3

Nitra, Slovaca Universitas Agriculturae Nitriae, 2017, pp. 63-68

\title{
THE INFLUENCE OF PHYSICAL FATIGUE ON WORK ON A PRODUCTION LINE
}

\author{
Sabina KOŁODZIEJ ${ }^{1 *}$, Mariusz J. LIGARSKI ${ }^{2}$ \\ 'Kozminski University, Warsaw, Poland \\ ${ }^{2}$ Silesian University of Technology, Zabrze, Poland
}

\begin{abstract}
The purpose of this study is to determine the factors having impacts on the physical fatigue of employees and to analyse its influence on work on a production line. In order to carry out these objectives, a comprehensive research was conducted in a medium enterprise producing processed fruit and vegetable products. Air temperature and humidity tests, employee survey, production line productivity measurements, and other observations were performed. Large variations in temperature and humidity were observed during the analysed period. Analysing the survey results, attention was paid to the declared length of sleeping of employees after each shift, the time when they feel fatigue and the factors that, according to respondents, have the greatest impact on the work performed. Attempts were made to determine the wellbeing of employees and to indicate the disturbing symptoms. Special attention was paid to the negative phenomena felt by respondents. The main factors affecting the physical fatigue of employees were identified and described. We sought to explain the impacts of physical fatigue on work on the production line. Improvements, which should help to reduce fatigue and improve working conditions, have been proposed. The analysis provided interesting information that could be used in various food manufacturing companies.
\end{abstract}

Keywords: production engineering; production organisation; ergonomics; food industry; fatigue; shift work

A large number of food processing plants operate in shift working time. This implies a number of consequences, not only in terms of organisation and work efficiency, plant operation legal regulations, energy consumption, etc., but it also affects the wellbeing of employees working in different times of day or night. All of these factors can significantly influence the quality of production processes as well as the overall outcome of conducted business activity, reflecting the profitability of a given business. Therefore, it is important to undertake research to deepen the existing knowledge about the impacts of psychological variables, including shift work fatigue, on the productivity and wellbeing of employees working in the shift system.

Available literature clearly indicates that shift work has many negative impacts on employees. The most significant consequences include: higher psychological costs for work performance; higher incidence of gastrointestinal problems; higher stress levels; reduced body immunity; lower sleep quality; and hormonal disturbances associated with sleep and wake control (Juslén et al., 2007; Murray and Thimgan, 2016).

As a result, the shift work is also associated with a decreased productivity as well as higher incidence of employees' low job satisfaction in comparison to non-shift workers (Rutenfranz et al., 1978; Weiner, 1984; Folkard and Monk, 1985; Dall'Ora et al., 2016). The majority of the mentioned negative correlations of the shift work is related to the disturbance of the natural rhythm of sleep and wakefulness. The research on ergonomics, including the information presented by Otto Graf, shows that the highest productivity is achieved in the morning ( 8 a.m.-10 a.m.), i.e. during the first shift. This productivity is higher than the average productivity by $30 \%$. Approximately at noon, it decreases and then rises to the maximum between 12 a.m. and 2 p.m. During the second shift, the maximal productivity is observed around at 6 p.m., and then it constantly decreases till 3 a.m. After this time, the productivity again increases, reaching a high level in the morning. The shift work interferes with the natural pattern of human activity, forcing to work at significantly reduced levels of body performance, especially during the night. The workers who frequently attend the night shifts have sleeping issues and lack of full body regeneration leads to fatigue, both physical and mental.

As defined by the literature, physical fatigue appears due to excessive muscles overload (Schultz and Schultz, 2011). There are two types of fatigue: central and peripheral one. The central fatigue refers to the feeling of muscle pain and difficulties in the work performed. This type of fatigue is responsible for the decrease in concentration, attention, motivation and psychomotor efficiency. Vice versa, the peripheral fatigue leads to a decrease in muscle strength and muscle contraction due to fatigue (Koradecka, 1999). Fatigue does not increase gradually during the working day, but it appears and disappears at certain times. According to the results of the so far performed research, in case of the first shift, the vast majority of manual workers experience the greatest fatigue at the start of the shift, before the lunch break and at the end of the day. Therefore, physical work requires breaks providing recovery before the employees 
would be fully overcome by fatigue (Schultz and Schultz, 2011).

Mental fatigue is often compared to boredom, and not only factors related to the type of work performed but also organisational issues are based on it. Most researchers have observed strong boredom in case of work associated with low level of challenges, poor supervision and poor work control, negative evaluation of work by the superior, poor salary and low cognitive requirements for work, and inability to make decisions (Schultz and Schultz, 2011). It has also been found that the improvement of physical work conditions, such as the reduction of noise, better lighting and more pleasant environment, can contribute to reduction of negative effects of routine and monotonous tasks. Also, friendly relationships and job rotation can lead to lowering the level of mental fatigue (Schultz and Schultz, 2011).

The purpose of the study is to determine the factors affecting the physical fatigue of employees, based on the research conducted in the vegetable and fruit processing company, and to analyse how the fatigue affects the work on the production line.

\section{Material and methods}

The research was conducted in a medium-sized food company, the main activity of which is the production of a wide range of vegetable and fruit products. The company has not provided the permission for use of its name, so the term "ABC" will be used in order to refer to it. The $A B C$ company was established in 1991, its registered office and three branches are residing in Silesia in Poland. It is involved in production, trade, import and export and employs approximately 480 people. The company puts great importance to the quality of manufactured products; it is certified by IFS Food Version 6 and BRC Global Standard for Food Safety Issue 7. The enterprise has four brigades working in a three-shift system. The production process consists of the following stages: washing, sorting, jarring, weighing, dosing of pickle, jar closing, pasteurisation, storage, labelling and foiling, and shipping. The company has conducted the following examinations: air temperature and humidity measurements at all three shifts, surveys on a group of 45 employees, productivity measurement on the production line, and others, including the examination of the quantity of glass breakages caused by employees at the company premises. The research was conducted in July and August 2016 and was performed as part of an engineering project supervised by Mariusz Ligarski, assistant professor, engineer. Surveys were carried out within the company facilities. A paper questionnaire was given to a group of 45 employees and it was anonymous and contained closed questions; respondents selected the previously prepared potential answers. The employees were asked to indicate their gender, age, years of service, workstation, the system in which they work and the extent of their work. The questions dealt with the average length of sleep after each shift, the time of greatest fatigue, the time of peak performance, the factor that most influences the work and the wellbeing. Some of the results of the survey were used for the purpose of this study.

\section{Results and discussion}

The examinations included the temperature and humidity measurements at the $A B C$ company, directly on the production floor, at the production line for each of the shifts, between 2 July 2016 and 5 August 2016. The measurements were conducted twice: once in the first part of the shift and once in the second part of the shift. The results confirm that temperature and humidity fluctuated significantly. The lowest recorded temperature was $22.8{ }^{\circ} \mathrm{C}$ during the first shift and the highest was $31^{\circ} \mathrm{C}$ during the second shift. The average temperature in the analysed period was $26.3^{\circ} \mathrm{C}$. The air humidity varied between $61 \%$ and $79 \%$ and its mean value was approx. $69 \%$. The obtained results indicate that the limit values specified by the company have been exceeded $-26^{\circ} \mathrm{C}$ for temperature and $65 \%$ for air humidity. Excesses, both in temperature and humidity, affected the quality of work of the people employed.

Analysing the results of the survey, $51.1 \%$ of respondents accounted for women and $48.9 \%$ accounted for men. 55.6\% of the respondents accounted for people who work on rotary workstations, performing different works; the remaining $44.4 \%$ were fixed work schedule employees. The average declared lengths of sleep after the first (6 a.m.-2 p.m.), second ( 2 p.m. -10 p.m.) and third shift (10 p.m. -6 a.m.) (Table 1) were compared.

The analysis of the results shows that employees need the lowest amount of sleep after work on the first shift. Fatigue after work on the second and third shift is greater; therefore, the employees need more sleep. Particularly noticeable is the increase in sleep demand after the third shift, over 8 hours. Employees from this group, at the end of the third shift need most sleep due to high fatigue after work.

The next question of the survey asked the employees to determine when they felt the greatest fatigue. $61.5 \%$ of the respondents feel the greatest physical fatigue after the third shift, $23.3 \%$ of respondents after the first shift, and $15.2 \%$

Table 1 Summary of responses regarding the declared average amount of sleep of employees after each shift

\begin{tabular}{|l||c|c|c|}
\hline $\begin{array}{l}\text { Average length } \\
\text { of worker's sleep }\end{array}$ & $\begin{array}{c}\text { After the first } \\
\text { shift in \% }\end{array}$ & $\begin{array}{c}\text { After the } \\
\text { second shift in \% }\end{array}$ & $\begin{array}{c}\text { After the third } \\
\text { shift in \% }\end{array}$ \\
\hline 5-6 hours & $68.9 \%$ & $41.5 \%$ & $61 \%$ \\
\hline 7-8 hours & $28.9 \%$ & $51.2 \%$ & $24.4 \%$ \\
\hline More than 8 hours & $2.2 \%$ & $7.3 \%$ & $14.6 \%$ \\
\hline
\end{tabular}

Source: own elaboration 




Fig. 1

The percentage of respondents declaring when they feel the greatest physical fatigue (after the first, second and third shift) Source: own elaboration

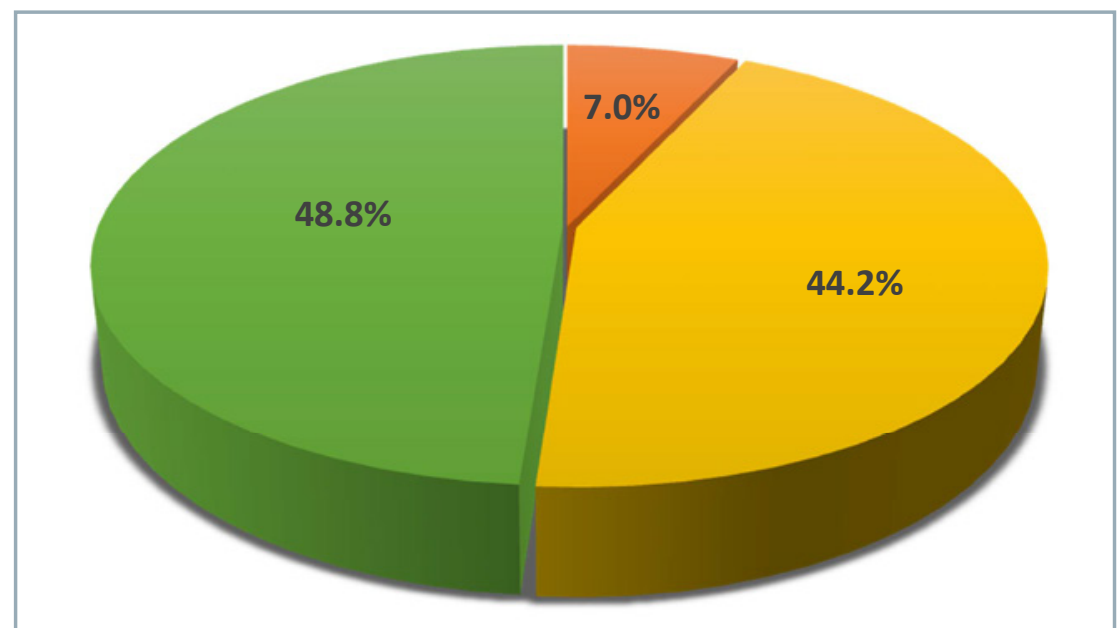

Fig. 2 The percentage indications of the highest productivity in the first, second and third shift

Source: own elaboration

of respondents after the second shift (Fig. 1).

The next question asked the employees to determine when they reach the highest productivity. $48.8 \%$ of the respondents declare that the highest productivity is obtained during the second shift, $44.2 \%$ of respondents declared that after the first shift, and $7 \%$ of respondents declared after the third shift (Fig. 2).

The analysis of those results confirms that the greatest fatigue and the lowest productivity are obtained during the third shift. The respondents best evaluate the second shift, and slightly worse the first shift. This is probably related to the time of the shifts - the second shift takes place since 2 p.m. till 10 p.m., and the days. The results are presented in Table 2 ; the respondents answered questions using the following scale:

1. a little, moderately;

2. on average;

3. significantly;

4. very much.

By analysing the results, it should be stated that $31.1 \%$ of the respondents feel a significant fatigue and $15.6 \%$ are very tired. The employees suffer from spinal pain, hand aches, and muscle aches. None of the respondents felt very relaxed, only $8.8 \%$ of the respondents stated that they were in very good shape, a similar number of indications were received by the statement - I felt vigorous to the highest degree - very much. The answers show that some of the employees are clearly tired and feel pain. Working on a production line is a difficult job where a relatively large group of employees is experiencing negative effects.

The productivity at the workstation was measured on the production line. The measurement was conducted on a group of approximately 30 people, who worked at the canned cucumbers production line since 18 July 2016 till 11 August 2016. The surveyed group was working in a three-shift fourbrigade system and their work involved the filling of cucumbers into the jars. The piecework system made it possible to measure the number of jars with the filling - the imposed standard was 700 jars. The employees productivity was calculated at each shift based on the imposed standard in the period considered. The following productivity results were obtained: the first shift 701 jars; the second shift - 690 jars; the third shift -630 jars (Fig. 3).

When analysing these results, it has to be stated that the lowest productivity was reached during the third shift and the highest one during the first shift.

Interesting information can be also provided by comparing the number of glass breakages caused by employees in the production hall in July and August 2016 (Table 3).

The analysis of the results shows that breakages occurred most frequently during the third shift, and they were least frequent during the first shift. Large fatigue during the third shift causes a significant increase in 
Table 2 Summary of answers to questions about the wellbeing of employees

\begin{tabular}{|c|c|c|c|c|c|}
\hline \multirow[t]{2}{*}{ Item } & \multirow[t]{2}{*}{ State of wellbeing } & \multicolumn{4}{|c|}{ Answers } \\
\hline & & 1 & 2 & 3 & 4 \\
\hline 1 & I feel tired & $13.3 \%$ & $40.0 \%$ & $31.1 \%$ & $15.6 \%$ \\
\hline 2 & My muscles ache & $46.6 \%$ & $22.2 \%$ & $15.6 \%$ & $15.6 \%$ \\
\hline 3 & My legs are "weak" & $53.3 \%$ & $22.2 \%$ & $17.8 \%$ & $6.7 \%$ \\
\hline 4 & I feel relaxed & $53.3 \%$ & $26.7 \%$ & $20.0 \%$ & $0.0 \%$ \\
\hline 5 & I feel like "worn out" & $44.4 \%$ & $26.7 \%$ & $8.9 \%$ & $20.0 \%$ \\
\hline 6 & I feel spinal pain & $31.1 \%$ & $31.1 \%$ & $11.1 \%$ & $26.7 \%$ \\
\hline 7 & I cannot concentrate & $58.8 \%$ & $23.4 \%$ & $15.6 \%$ & $2.2 \%$ \\
\hline 8 & I am forgetful & $70.5 \%$ & $18.2 \%$ & $6.8 \%$ & $4.5 \%$ \\
\hline 9 & I feel hand pains & $42.2 \%$ & $33.3 \%$ & $6.7 \%$ & $17.8 \%$ \\
\hline 10 & I got tired very quickly & $62.2 \%$ & $24.4 \%$ & $13.4 \%$ & $0.0 \%$ \\
\hline 11 & I had poor performance & $57.8 \%$ & $31.1 \%$ & $6.7 \%$ & $4.4 \%$ \\
\hline 12 & I am rested & $51.1 \%$ & $26.7 \%$ & $20 \%$ & $2.2 \%$ \\
\hline 13 & I felt I could do a lot in one day & $24.4 \%$ & $40.0 \%$ & $20.0 \%$ & $15.6 \%$ \\
\hline 14 & I felt that I was in good shape & $26.7 \%$ & $37.8 \%$ & $26.7 \%$ & $8.8 \%$ \\
\hline 15 & I felt full of vigour & $51.1 \%$ & $22.2 \%$ & $17.8 \%$ & $8.9 \%$ \\
\hline
\end{tabular}

Source: own elaboration

Table 3 Glass breakages caused by employees in the production hall in July and August

\begin{tabular}{|c|c|c|c|}
\hline \multirow[t]{2}{*}{ Type of shift } & \multicolumn{2}{|c|}{ Number of glass breakages in a month } & \multirow[t]{2}{*}{ Total } \\
\hline & July & August & \\
\hline I & $151 \mathrm{pcs}$ & 148 pcs & 299 pcs \\
\hline II & 187 pcs & 173 pcs & 360 pcs \\
\hline III & 196 pcs & 201 pcs & 397 pcs \\
\hline
\end{tabular}



Fig. 3 Productivity reached during the first, second and third shift Source: own elaboration the number of glass breakages on the production line.

Summarising the research conducted, the possible causes of physical fatigue were illustrated using the Ishikawa Diagram. The Ishikawa Diagram is one of the basic statistical methods in quality management (Prístavka et al., 2016). Four main causes were identified: man, work system, work organisation, and physical factors of the workplace. Man is affected by fatigue, pain, insufficient sleep, stress and the lack of motivation. The system of work imposes work on shift and piecework system. The work organisation is affected by the lack of rotation of workstations, non-functional system of breaks, mismatched seat. Physical factors of the workplace include temperature, noise, lighting and humidity. Those factors have an evident effect on 
worker's physical fatigue, especially in the case of being affected by more of them. As a result of the excessive workload of the human body, many changes occur, both in the musculoskeletal and nervous systems. Consequently, the following physical fatigue results occur:

- decrease in work productivity;

- increase in the number of errors;

- loss increase (glass breakage);

- increase in accidents during work time.

In order to reduce the impacts of the factors adversely affecting the physical fatigue, the $A B C$ company is proposed the following:

- making regular measurements of temperature, noise and humidity and taking adequate measures to keep the physical environment at the appropriate level;

- introducing a new break system that will provide employees with the opportunity to rest and replace fluids and food (the third shift requires a special treatment);

- considering the possibility of job rotation;

- a better profiled seat for the employees on the production line and a more ergonomic workstation;

- proposing a short set of muscle relaxation exercises that could be performed by employees;

- considering the possibility of music playing for the staff, in due time, for their relaxation and recovery.

\section{Conclusion}

The research was undertaken to analyse the presence of factors affecting the employees' fatigue in the selected food manufacturing plant and the effect of this fatigue on the employees working on shifts on the production line. The analysis is based on the results of a survey conducted on 45 employees working in the three-shift work system. In addition, data on physical conditions of the work performance (temperature, humidity) and productivity (number of filled jars, number of glass breakages) was collected in the survey.

According to the survey results, the employees declared the greatest fatigue level after the work on the third shift. The third shift was also associated with the highest sleep demand after work (over 8 hours). The above subjective assessments are consistent with the objective data collected during the survey, which indicates that the third shift work is characterised by the lowest productivity and the highest quantity of glass breakages. Those arrangements are part of the existing literature presented in the first part of the study. The shift work, especially the night shift, is associated with the jet lag syndrome, characterised by irritability, decreased muscle strength and deterioration of visual and motor coordination (Zużewicz and Zużewicz, 2016). All of the above-mentioned temporal effects lead to reduced productivity and more errors, as it is shown by the research presented.

The analysis of responses to questions about work during the second shift showed the lowest declared fatigue and the highest subjective productivity. As for the reported sleep demand, a much higher number of sleep indications of 7-8 hours was observed in comparison to the first shift. However, the collected objective data indicates that the highest productivity, as measured by the number of filled jars and glass breakages, occurred during the first shift within the analysed period. However, it should be noted that the difference between the first and the second shift in the measurement of objective productivity indicators was relatively small. However, there is a discrepancy between the subjective assessment of one's own work and the objective indicators of that work despite the example of this data.

It seems that one of the factors contributing to employee's preference for the second shift over the first one may be the time when it starts. Zużewicz and Zużewicz (2016) claim that the morning shift starting at 6 a.m., similarly to the analysed workplace, affects the sleep deficit. The duration of the REM (Rapid Eye Movement) phase, which is important for mental wellbeing and cognitive functioning, is mainly reduced, which can directly affect functioning at the workplace. According to Zużewicz and Zużewicz (2016), initiating the morning shift one hour later allows for a significant reduction of this deficit of sleep. Perhaps the sleep deficit felt by the employees of the morning shift affects the subjective improvement of evaluation of the second shift, although - in line with the present data - the morning shift is conducive to achieving the highest productivity.

The conducted survey also analysed which of the selected factors influence the employees' level of fatigue. The focus is on the perception of employees since the assessment of physical working conditions is one of motivating factors for work. According to the classic twofactor Herzberg theory, eliminating the dissatisfaction of employees related to hygiene factors is essential for improving the work performance. Respondents' responses confirm the importance of physical working conditions as temperature and noise are considered the factors that have the most significant influence on work productivity.

The analysis of declared respondents' fatigue level related to the work performed allows characterising the examined employees as rather tired, with reduced energy level, experiencing some painful symptoms. The work performed undoubtedly mitigates the wellbeing, not only because of the shift and its negative already discussed consequences. An additional factor is also the nature of manual work, performed in the piecework system, by a significant part of employees in a fixed work pattern. As it has already been emphasised, fatigue resulting from the performance of monotonous work under difficult physical conditions increases the employee's tiredness. That is why it seems so important to provide the appropriate working conditions in line with the demands set out above.

All in all, the presented survey provided information on the fatigue perception by the food industry employees. It showed subjective factors influencing the level of that fatigue. In addition, it pointed to an interesting divergence between subjective and objective evaluation of efficiency of the work performed in the shift system. The results were used to formulate proposals to mitigate the negative consequences of shift work, improve the employees' wellbeing, productivity and quality of work (Ligarski, 2013; Górny, 2014).

The presented survey has some limitations that affect how the results are interpreted. The survey was conducted in a single production plant, the specificity of which certainly determined the answers given by respondents. Although 
data relating to differences in work productivity and post-shift fatigue levels coincide with the existing findings presented in literature, the application of proposed solutions to other production plants should be preceded by careful analysis. However, due to the importance of the problem, the presentation of the results of above research complements the knowledge of the factors and consequences of fatigue on shift employees and the perception of this phenomenon by respondents.

\section{Acknowledgments}

This article is a result of research conducted at the Institute of Production Engineering, Faculty of Organization and Management, Silesian University of Technology within the statutory work entitled "Methods and tools for improving products and services on the selected examples" (identification 13/030/BK_17/0027).

\section{References}

DALL'ORA, CH. - BALL, J. - RECIO-SAUCEDO, A. - GRIFFITHS, P. 2016. Characteristics of shift work and their impact on employee performance and wellbeing: A literature review. In International Journal of Nursing Studies, vol. 57, pp. 12-27.

FOLKARD, S. - MONK, T. 1985. Hours of Work: Temporal Factors in Work Scheduling. New York: Wiley.

GÓRNY, A. 2014. Application of quality shaping methods in the work environment improvement. A case of theoretical frames. In Management Systems in Production Engineering, vol. 3, no. 15, pp. 106-111.
JUSLÉN, H. T. - VERBOSSEN, J. - WOUTERS, M. C. H. M. 2007. Appreciation of localised task lighting in shift work - A field study in the food industry. In International Journal of Industrial Ergonomics, vol. 37, no. 5, pp. 433-443.

KORADECKA, D. 1999. Work Safety and Ergonomics. Warszawa: CIOP (In Polish: Bezpieczeństwo pracy i ergonomia).

LIGARSKI, M. J. 2013. Problems examination in quality management system. In Acta Technologica Agriculturae, vol. 16, no. 4, pp. 106-110.

MURRAY, S. - THIMGAN, M. S. 2016. Human Fatigue Risk Management. Improving Safety in Chemical Processing Industry. Elsevier, Academic Press.

PRÍSTAVKA, M. - KOTOROVÁ, M. - SAVOV, R. 2016. Quality control in production processes. In Acta Technologica Agriculturae, vol. 19, no. 3, pp. 77-83.

RUTENFRANZ, J. - COLQUHOUN, Q. - KNAUTH, P. - GHATA, J. N. 1978. Biomedical and psychosocial aspects of shift work. A review. In Arzneimittelforshung, vol. 28, no. 10a, pp. 1867-1872.

SCHULTZ, D. P. - SCHULTZ, S. E. 2011. Psychology and Work Today. Warszawa: PWN (In Polish: Psychologia a wyzwania dzisiejszej pracy).

WEINER, E. 1984. Vigilance and inspection. In J.Warm (Ed.), Sustained Attention in Human Performance. New York: Wiley, pp. 207-224.

ZUŻEWICZ, M. A. - ZUŻEWICZ, K. 2016. Chronobiological aspects of health risk in night shift workers. In Work Safety, vol. 4, pp. 12 17. (In Polish: Chronobiologiczne aspekty ryzyka zdrowotnego u pracowników zmianowych nocnych. Bezpieczeństwo pracy). 